\title{
"A SALA DE AULA NO ARQUIVO": ANÁLISE DE UMA EXPERIÊNCIA DO ARQUIVO PÚBLICO DO ESTADO DE SÃO PAULO COM ALUNOS DA EDUCAÇÃO BÁSICA
}

\author{
"THE CLASSROOM AT THE ARCHIVES": \\ AN EXPERIENCE ANALYSIS OF THE SÃO PAULO STATE PUBLIC ARCHIVES \\ WITH STUDENTS OF BASIC EDUCATION
}

Stanley Plácido da Rosa Silva ${ }^{1}$ Andresa Cristina Oliver Barbosa²

\begin{abstract}
RESUMO: O artigo analisa o programa "A sala de aula no Arquivo", realizado pelo Arquivo Público do Estado entre os anos de 2013 e 2015, cujo objetivo era a problematização de documentos de arquivo em seus variados usos na construção do conhecimento histórico em sala de aula. Do mesmo modo, propõe uma reflexão sobre a importância do diálogo entre Arquivos e escolas.
\end{abstract}

Palavras-chave: Arquivos permanentes; Difusão cultural; Mediação da informação; Ensino de história.

\begin{abstract}
The article analyzes the program "The classroom at the Archives", carried out by the State Public Archives between the years of 2013 and 2015, whose objective was the problematization of archive documents concerning their various uses in the construction of historical knowledge in the classroom. In the same way, it proposes a reflection on the importance of a dialogue between Archives and schools.
\end{abstract}

Keywords: Permanent Files; Cultural Diffusion; Mediation of Information; History Teaching;

Arquivos registram decisões, ações e memórias. Arquivos são um património [patrimônio] único e insubstituível transmitido de uma geração a outra. Documentos de arquivo são geridos desde a criação para preservar seu valor e significado. Arquivos são fontes confiáveis de informação para ações administrativas responsáveis e transparentes. Desempenham um papel essencial no desenvolvimento das sociedades ao contribuir para a constituição e salvaguarda da memória individual e coletiva. $O$ livre acesso aos arquivos enriquece $o$

\footnotetext{
${ }^{1}$ Doutor em História Econômica pela Universidade de São Paulo (USP). Executivo Público do Arquivo Público do Estado de São Paulo de 2010 a 2018. Atualmente é Coordenador Acadêmico do Instituto do Legislativo Paulista (ILP/ALESP).

2 Mestra em História pela Pontifícia Universidade Católica de São Paulo (PUC-SP). Servidora do Arquivo Público do Estado de São Paulo desde 2008, atuando como Diretora Técnica do Núcleo de Ação Educativa no período de 2009 a 2015.
} 
conhecimento sobre a sociedade humana, promove a democracia, protege os direitos dos cidadãos e aumenta a qualidade de vida. (CONSELHO INTERNACIONAL DE ARQUIVOS, 2010)

A citação com a qual iniciamos esse texto é o trecho inicial da Declaração Universal de Arquivos, aprovada na Assembleia Internacional de Arquivos, ocorrida em setembro de 2010 em Oslo. Nela ficam bem delineadas as duas funções precípuas das instituições arquivísticas: registro das ações da entidade produtora ou acumuladora da documentação, ou seja, sua função administrativa e estratégica para o administrador e, do mesmo modo, seu papel de "salvaguarda da memória individual e coletiva", função aqui entendida em termos de promoção da cidadania.

Os arquivos públicos ainda são "ilustres desconhecidos" para além do círculo acadêmico de pesquisadores que utilizam sua documentação para fins científicos ou jornalísticos. De acordo com Bacellar, "Para a maioria da população, são inteiramente ignorados ou, quando muito, tidos como sinônimo de depósitos de papéis velhos e amarelados, voltados exclusivamente para os chamados "ratos" de Arquivo, ou seja, historiadores e outros poucos interessados" (2012, p. 266).

Uma forma de superar tal concepção é a promoção de ações que permitam aos arquivos dialogarem com a sociedade na qual estão imersos. Em síntese: investir em ações de difusão e de ação educativa de forma a tornar tanto a instituição quanto o seu acervo conhecidos e disponíveis à população em geral, sendo as instituições escolares, a nosso ver, um público privilegiado na construção de Arquivos que se coadunem aos princípios democráticos (BARBOSA; SILVA, 2012; BARBOSA; PEREIRA, SILVA, 2014).

Assim, este trabalho tem como objetivo analisar uma proposta pedagógica desenvolvida pelo Arquivo Público do Estado de São Paulo, entre os anos de 2013 e 2015, denominada "A sala de aula no Arquivo", tendo como fonte para a pesquisa, além da bibliografia a respeito da temática, as fichas de avaliação preenchidas pelos professores. 
Direcionada preferencialmente a alunos dos ensinos Fundamental II e Médio na disciplina de História, tinha como mote uma dupla problematização: a importância de documentos de arquivo em seus variados usos para a construção do conhecimento histórico na sala de aula e o papel a ser desempenhado por uma instituição arquivística na gestão e preservação do patrimônio documental. Para isso, avaliaremos os pressupostos teórico-metodológicos que embasavam a proposta, os resultados que ela alcançou por meio da avaliação das escolas que dela participaram, refletindo, também, sobre a importância do diálogo entre Arquivo e Educação.

\section{Ensino de História no Brasil: trajetória e relação com os arquivos}

A busca pela compreensão dos acontecimentos relacionados ao ser humano no passado existe desde muito tempo na história da humanidade e remonta pelo menos há dois milênios antes de Cristo. Entretanto, sua constituição como saber objetivamente elaborado e teoricamente fundamentado ocorreu somente a partir do século XVIII (FONSECA, 2004, p. 21). No Brasil, seu início é datado do século XIX, motivado principalmente pelo papel de "formação nacional" que acompanhava a disciplina. Logo, de forma subsequente à Europa, sua transformação em disciplina escolar no país aconteceu no período pós-Independência (1822) e se cristalizou com a criação, quase concomitante, do Instituto Histórico e Geográfico Brasileiro (IHGB) e do Colégio Pedro II, ambas as instituições existentes até hoje (ABUD, 2005, p. 29-30).

A interdependência entre as instituições ocorria de tal forma que os membros do IHGB eram os professores do Colégio. Nesse sentido, a missão de delinear o que seria ensinado sobre a História do Brasil desse período em diante coube a um de seus membros, Von Martius que, em 1843, venceu o concurso "Como se deve escrever a História do Brasil", promovido pelo próprio IHGB. Grosso modo, o autor afirmava que o ensino de História deveria priorizar a formação étnica do Brasil, com as respectivas 
contribuições do branco, do negro e do índio. Do mesmo modo, aconselhou que o papel dos portugueses no descobrimento, colonização e transferência de suas instituições administrativas deveriam ser abordados. Por fim, destacou o papel dos jesuítas no país e a importância de se estudar as relações entre a Monarquia e a Igreja em terras brasileiras (ABUD, 2005, p. 30-31).

Os norteamentos a serem seguidos no Ensino de História permaneceram quase inalterados até o Estado Novo varguista, quando o currículo do Colégio Pedro II, moldado pelo IHGB, deixou de ditar as regras no âmbito nacional. A partir dessa data, o Estado, interessado em formar um novo cidadão, buscou desenvolver, por meio das disciplinas de História e Geografia, um indivíduo pautado pelos valores nacionalistas.

Com o advento do regime civil-militar no país, em 1964, a disciplina sofreu novas mudanças, sendo inseridas as noções de preservação da segurança nacional, valorização da pátria e dever de cumprir e obedecer a legislação. Mais que isso, perdeu-se a especificidade da História em sua junção com a disciplina de Geografia, originando a criticada "Estudos Sociais", a qual estaria encarregada de trabalhar os deveres do cidadão, eliminando, desse modo, o caráter crítico das duas disciplinas em nome da construção do ideal de uma nação harmônica (FONSECA, 2004, p. 55-58). A intenção do governo, à época, era formar um aluno passivo diante de uma História eurocêntrica, na qual seu papel fosse apenas o de receptor e não o de questionador. Apesar de esboçar o uso de eixos temáticos, a concepção de ensino adotada manteve o eixo "político" como elemento central de estudos (ABUD, 1996, p. 494-498).

O final da década de 1970 e o decorrer dos anos 1980 foram marcados pela luta da redemocratização do país, assim como pelo debate referente a uma nova organização da sociedade. Dentro desse contexto, a relação entre movimento social e Educação foi reconhecida por meio do trabalho desenvolvido nas Comunidades de Bases da Igreja Católica, nas associações docentes de todos os níveis, na Educação popular, nas lutas pelas "Diretas Já", entre outros segmentos. Dessa forma, sujeitos vindos 
dessas ações coletivas, que extrapolaram o ambiente da fábrica ou os locais de trabalho, passaram a demandar do poder público o atendimento de suas necessidades (GOHN, 2011, p. 334).

Cumpre ressaltar que o movimento de transformação experimentado pela História na condição de disciplina escolar não ocorreu, contudo, de forma deslocada em relação à historiografia. No Brasil, décadas mais tarde em relação à Europa, mais precisamente a partir dos anos 1970, a renovação historiográfica também ocorreu e os historiadores brasileiros, influenciados pelas escolas inglesa e francesa, também passaram a abordar questões sociais, culturais e do cotidiano as quais impactaram, por sua vez, na formulação do que deveria ser trabalhado e ensinado na Educação Básica. (RIBEIRO, 2004, p. 85). A renovação na História ensinada é caudatária, portanto, das transformações do campo historiográfico.

A partir dessa conjuntura, novas discussões surgiram dentro do campo da Educação com propostas de repensar as questões acerca da autonomia da escola e a descentralização do sistema de ensino, desdobrando-se nos debates concernentes aos currículos escolares em todas as áreas do conhecimento. Reivindicava-se, sobretudo, uma escola criativa, inclusiva e democrática e um ensino de qualidade.

Diante desse cenário e com o crescente movimento pela redemocratização, o sistema de ensino brasileiro também inseriu em sua pauta de discussão elementos com vistas a fomentar a construção de uma "educação para a cidadania", na qual as potencialidades dos educandos em termos de crenças, valores e práticas deveriam ser trabalhadas de forma a permitir-Ihes viver de forma plena e consciente em sociedade (BENEVIDES, 1996, p. 225).

Entre os anos de 1985 e 1995, reflexões acerca da reforma curricular para os ensinos de $1^{\circ}$ e $2^{\circ}$ graus - atuais Ensinos Fundamental e Médio foram realizadas em todos os estados brasileiros. O debate sobre o ensino voltou-se para o questionamento dos conhecimentos escolares: tanto no âmbito teórico como no metodológico (RIBEIRO, 2004, p. 85; BARBOSA; SILVA; 2012, p. 57). 
As reformas no ensino paulista começaram em 1983, no governo de André Franco Montoro, com a criação do ciclo básico, que consistia num projeto político com o objetivo de modificar as relações excludentes do Ensino Fundamental, marcado até então pela reprovação escolar (DURAN; ALVES; PALMA FILHO, 2005, p. 83). Três anos depois, em 1986, teve início a reformulação dos Guias Curriculares, usados, desde a década de 1970, como instrumentos de orientação pedagógica acerca dos referidos níveis de ensino. Após vários anos de discussões, esses Guias passaram a ser denominados de Propostas Curriculares, apresentadas em forma de fascículos, sendo um para cada conteúdo do núcleo comum, organizados segundo propostas que incorporaram os princípios das teorias críticas do currículo (PALMA FILHO, 1989)

A renovação das propostas curriculares dos ensinos de $1^{\circ}$ e $2^{\circ}$ graus trouxe o rompimento do referencial técnico-linear presente nos Guias Curriculares da década de 1970. As novas propostas colocaram em discussão diversos conceitos, como aluno, professor e ensino, os quais foram guiados por algumas questões, dentre as quais se destacavam o fim do mito da neutralidade no ensino, a necessidade de o conteúdo se articular a realidade do aluno, a importância da dialética no processo de ensinoaprendizagem e a concepção de que o aluno deveria ser visto como sujeito ativo na produção do conhecimento (PALMA FILHO, 1989, p. 136-137).

Foi a partir das transformações ocorridas no campo historiográfico que outra discussão se encaminhou: a concepção de fonte documental. Até esse momento, o documento, que era concebido como prova e entendido como verdade passou a ser analisado criticamente; sendo um deles o seu contexto de produção (LE GOFF, 2003; BARBOSA; SILVA, 2012).

Assim, a Coordenadoria de Estudos e Normas Pedagógicas (CENP), em 1984, reuniu representantes de Diretorias de Ensino do Estado, professores da área da Educação, além de sua equipe técnica de História ${ }^{3}$,

\footnotetext{
3 Entre os anos de 1985 e 1986, deu-se início ao processo de uma nova Proposta Curricular para o Ensino de História. A Equipe Técnica de História era composta por professores ligados à área de pesquisa e Ensino de História, com vasta experiência docente na rede pública de ensino e ligados à Associação Nacional de Professores Universitários de História
} 
com vistas à reformulação do currículo de História. A partir dos resultados obtidos dessa reunião, e de várias outras, foi publicada, em 1989, a Proposta Curricular para o ensino de $1^{\circ} \mathrm{grau}$, sendo pautada na revisão de questões concernentes ao processo de ensino-aprendizagem, produção do conhecimento e concepção de História. (BARBOSA; SILVA; 2012, p. 57). Dessa forma, optou-se por uma proposta pedagógica que superasse

[...] o divórcio assumido entre os três graus de escolaridade no que se refere ao ensino e à pesquisa, onde passivamente cabe ao $1^{\circ}$ e $2^{\circ}$ graus 0 ensino como transmissão de informações, e ao $3^{\circ}$ grau fica reservado o privilégio da pesquisa e da consequente produção do conhecimento [...] se opõe à cristalização de dados, fatos e ideias como verdades absolutas e acabadas, criando um pensamento reflexivo e atitudes questionadoras que recoloquem continuamente professores e alunos perante o conhecimento como histórico [...] ao estabelecer uma relação crítica com a segmentação passado/presente/futuro e com uma visão processual progressiva concebida em princípio/meio/fim teoricamente traçados, convive com 0 indeterminado, 0 indefinido, o diferenciado, dentro de uma perspectiva que a História é uma prática social e o vir a ser é construído pelo ser social em suas várias dimensões do presente (SÃO PAULO, 1989, p. 9).

A partir dessas considerações, temos, em primeiro lugar, a concepção do professor pesquisador e produtor de conhecimento. A relação ensinoaprendizagem é construída a partir de situações pedagógicas em que se reconhece o diálogo entre educador e educando como ferramenta essencial para o processo de ensino.

A construção do conhecimento histórico passou a ser entendida por meio da leitura e da interpretação de diferentes fontes documentais, as quais deveriam ser interrogadas e problematizadas para realmente condizerem com a revisão das concepções pontuadas pela Proposta. Todavia, essa proposta não foi implementada na rede de ensino estadual devido a existência de vários conflitos ideológicos e políticos (MARTINS, 1998). Em 1990, a CENP retomou a elaboração de uma nova proposta para a área do Ensino de História, tarefa na qual foi assessorada apenas por

(ANPUH), ao Sindicato dos Professores do Ensino Oficial do Estado de São Paulo (APEOESP), entre outras instituições. 
professores universitários - excluindo a participação de outros setores da sociedade, e principalmente, os professores da rede -, sendo a proposta definitiva finalizada e implantada depois de dois anos (SOUZA, 2006, p. 207).

A nova proposta, não obstante as críticas que a apontavam como um retrocesso da educação por reproduzir a ideologia conservadora do governo daquele período (GIGANTE, 1997), concebia a construção do conhecimento histórico articulado ao uso de diferentes linguagens, como documentos textuais, iconográficos, cartográficos, entrevistas etc.

Já na legislação federal também foram observadas mudanças no que concerne o Ensino de História. Por meio da Lei de Diretrizes e Bases de 1996 (LDB) e, posteriormente, dos Parâmetros Curriculares Nacionais (PCNs) competia à disciplina "[...] valorizar intercâmbio de idéias, sugerindo a análise e interpretação de diferentes fontes e linguagens - imagem, texto, objeto, música etc. - , a comparação entre informações e o debate acerca de explicações diferentes para um mesmo acontecimento" (BRASIL, 1998 , p. 60-61).

Alinhada às discussões no campo da historiografia, a reformulação das políticas educacionais e curriculares, a partir da década de 1990, trouxe nova perspectiva no que tange ao Ensino de História na sala de aula, assim como ao seu conceito. Os desafios eram os de superar a História tradicional pela História problema e concebê-la como processo, buscando as relações entre presente e passado. Os alunos passariam a ter condições de trabalhar as abordagens que são próprias da História como a percepção dos diferentes sujeitos envolvidos no contexto histórico, a historicidade dos fatos, a comprovação de hipóteses por meio de métodos (BEZERRA, [2004], p. 293).

Nesse movimento, as fontes documentais "passam a ser objeto de problematizações e estudos que visam apreender o seu processo de produção, as suas relações com a sociedade produtora e os indícios de situações que, a partir deles, podem ser interpretadas" (BARBOSA; PEREIRA, SILVA, 2014, p. 131). Assim, configuram-se de simples 
ilustrações contidas nos livros didáticos a elementos fundamentais na construção do saber histórico.

Buscando a relação entre Arquivos e Educação, entende-se que a reformulação das propostas curriculares impulsionou o diálogo entre ambos, já que os Arquivos passaram a ser entendidos como espaços em potencial para relação com a escola e detentores da matéria prima dos professores. Dessa forma, compreendendo que a utilização de documentos e os procedimentos adequados à sua leitura são fundamentais no processo de transformação do Ensino de História, os Arquivos assumem um papel fundamental no compromisso com a Educação, não só a superior como também a básica.

Para além da discussão sob as fontes documentais, os Arquivos, por meio de atividades pedagógicas, podem fomentar o uso do patrimônio documental na sala de aula e corroborar com o fortalecimento de seu lugar central quando o assunto é a preservação da memória e a garantia de direitos.

Ao encontro dessas concepções dialogamos com o entendimento de Alves, Brando e Menezes (2015, p. 14), que defendem a viabilidade de "educar e aprender a partir do patrimônio, aguçando e qualificando nossas formas de perceber, ler e intervir no mundo [...]". Ainda é relevante ressaltar que ações educativas quando realizadas em instituições arquivísticas, tendem a extrapolar a relação estabelecida com os documentos trabalhados, levando a "reflexões que podem ser utilizadas de forma interdisciplinar nos processos de ensino-aprendizagem, seja nas escolas ou em espaços não formais de educação, caracterizados pela intencionalidade do educar/aprender". Nesse sentido, em meio a essa conjuntura, o Arquivo Público do Estado, em um movimento também realizado por outras instituições congêneres ${ }^{4}$, deu início ainda na década de

\footnotetext{
${ }^{4}$ Destacam-se as ações empreendidas, por exemplo, pelo Arquivo Municipal "Washington Luís" da cidade de São Paulo e o Arquivo e o Arquivo Público da Cidade de Belo Horizonte, no qual as ações voltadas para o público escolar foram previstas na "missão" da instituição colocada na ocasião de sua criação, tendo em vista as discussões já colocadas desde meados dos anos 1980 .
} 
1990, às primeiras ações voltadas para o público escolar da educação básica, as quais foram intensificadas a partir dos anos $2000 .^{5}$

\section{A sala de aula no Arquivo}

O Arquivo Público do Estado de São Paulo possui sob sua guarda acervo datado do século XVI, resultado de sua função inicial de arquivo corrente da Secretaria de Governo da Capitania. No decorrer do tempo, sofreu diversas transformações em suas atribuições e no papel que representava para administração provincial e estadual. De órgão exclusivamente voltado para a guarda da documentação permanente, ampliou, nas últimas décadas seu escopo de atuação sendo, atualmente, o órgão central do Sistema de Arquivos do Estado de São Paulo, responsável pela preservação do patrimônio arquivístico, gestão documental e garantia do direito de acesso à documentação pública no âmbito estadual (SILVA; SILVA, 2016) além de recolher, gerir, preservar, divulgar, difundir e disponibilizar o patrimônio documental sob sua guarda. (SÃO PAULO, 2009).

Seu funcionamento é definido pelo decreto 54.276/2009, o qual estabelece que cabe ao Núcleo de Ação Educativa (NAE), entre outras funções, a elaboração de programas e ações que aproximem o público escolar da instituição e a promoção de visitas mediadas a estudantes e professores de instituições de ensino (SÃO PAULO, 2009), sendo tais ações entendidas no escopo das atribuições relacionadas à difusão do acervo ${ }^{6}$.

O programa "A sala de aula no Arquivo" ocorreu no período de abril de 2013 a maio de 2015 nas dependências do Arquivo Público do Estado de São Paulo (APESP), uma vez por semana, no período da manhã ou da

\footnotetext{
5 As considerações desse tópico não esgotam a problemática sobre o assunto. Nosso intuito foi apenas o de contextualizar, especialmente, o processo de transformação do Ensino de História e da concepção de fonte histórica, conceitos esses que embasam as questões teórico-metodológicas do objeto de estudo deste artigo.

6 É somente em 2009 que o Núcleo de Ação Educativa passa a existir no organograma do Arquivo, contudo as atividades oferecidas ao público escolar remontam ao final da década de 1980.
} 
tarde $^{7}$. O número de atendimentos podia variar conforme a demanda, desde que não comprometesse a rotina de trabalho dos demais setores da instituição nem colidisse com outras ações desenvolvidas pelo Núcleo de Ação Educativå .

Vinculada ao calendário escolar, haja vista seu público-alvo ser formado por estudantes da Educação Básica do $6^{\circ}$ ano do Ensino Fundamental ao $3^{0}$ ano do Ensino Médio, a sua oferta buscava ser harmônica às demais atividades oferecidas pelo Núcleo de Ação Educativa, as quais ocupavam os outros dias da agenda semanal de trabalho.

O programa consistia em uma oficina e uma visita mediada às instalações do Arquivo Público do Estado de São Paulo (APESP). A oficina, de duração aproximada de 50 minutos, era realizada com os alunos em sala de aula destinada para o atendimento de grupos, seguida de uma visita a alguns núcleos da instituição.

A primeira parte era realizada por, no mínimo, dois integrantes do Núcleo de Ação Educativa (NAE), ${ }^{9}$ a partir da documentação disponível no acervo da instituição. Para tal, foram disponibilizados os temas "Fontes Históricas", "Ferrovias Paulistas", "Movimento de 1932" e "Anistia e Redemocratização". As oficinas consistiam em uma sensibilização inicial

$7 \mathrm{O}$ atendimento era realizado preferencialmente às quartas-feiras - das $9 \mathrm{~h} 30$ às $11 \mathrm{~h} 30$ ou das $14 \mathrm{~h} 30$ às $16 \mathrm{~h} 30$.

8 Dentre as diversas atividades ofertadas, além do "A sala de aula no Arquivo", destacam-se: "Ateliê Infantil", atividade quinzenal para alunos do $1^{\circ}$ ao $5^{\circ}$ ano do Ensino Fundamental; "Conhecendo o DEOPS: memória e história" (em parceria com o Memorial da Resistência), também quinzenal, direcionada a alunos a partir do 90 ano do Ensino Fundamental; "Exposições Virtuais" semestrais tendo como público-alvo professores e estudantes em geral, com propostas de trabalho em sala de aula disponibilizadas a eles; "O Professor no Arquivo", de periodicidade mensal, voltada a graduandos e professores da Educação Básica; curso "O(s) uso(s) de documentos de Arquivo na sala de Aula", ofertado semestralmente com carga horária de 60 horas, nas modalidades presencial (graduandos e professores) e a distância (professores). Tais ações eram completadas pelas visitas monitoradas semanais abertas ao público em geral e pela Coleção "Ensino e Memória", publicação direcionada a professores composta por um texto escrito por especialista na temática escolhida, acrescido de atividades pedagógicas elaboradas a partir do acervo da instituição. Algumas das ações desenvolvidas pelo NAE podem ser analisadas em: Barbosa; Pereira; Menezes (2011); Barbosa; Silva (2012); Barbosa; Pereira; Silva (2014).

9 O projeto contemplava, inicialmente, a possibilidade de permitir ao professor, que assim desejasse, trabalhar outros temas com seus alunos e, da mesma forma, ele mesmo ministrar a oficina no lugar do servidor do NAE. Porém, para que isso ocorresse seria preciso que ele pesquisasse previamente as possibilidades oferecidas pelo acervo do APESP e preparasse a aula que seria de sua exclusiva responsabilidade, porém, sob a supervisão do NAE. 
sobre o assunto, seguida de contato com a documentação disponibilizada aos alunos, previamente selecionada quanto ao seu potencial pedagógico.

$\mathrm{Na}$ sala de aula, dedicava-se em torno de 15 minutos na explanação inicial para, em seguida, os alunos entrarem em contato direto com os documentos. Nesse momento, eles recebiam orientações para o uso correto de luvas e máscaras e o porquê de sua utilização. Somente depois os documentos, em kits que variavam de acordo com o tema escolhido, eram distribuídos entre os seis grupos nos quais geralmente os alunos eram organizados.

De forma a orientar a análise, e em razão também do tempo exíguo no qual a atividade era desenvolvida, os grupos de alunos, além da máscara e das luvas, recebiam uma ficha com quatro questões "norteadoras" cujas respostas, depois, eram socializadas com o restante da turma ao término da primeira etapa. As quatro perguntas, com variações mínimas a depender da faixa etária e do tema eram:

1) É possível saber se os documentos são da mesma época ou não? Como?

2) Quais as informações mais importantes retiradas de cada documento? Em qual deles foi mais fácil extrair informações? Por quê?

3) O que é possível saber sobre as épocas em que os documentos foram produzidos apenas lendo e/ou observando cada uma das fontes?

4) É importante que documentos como esses sejam guardados e abertos para consulta de todos? Por quê?

Durante os 30 a 35 minutos restantes, os alunos analisavam os documentos com o auxílio da equipe do NAE e dos professores responsáveis. De mesa em mesa, eram trabalhadas algumas estratégias para a obtenção de informações como o órgão produtor, o período em que ele foi produzido e o contexto histórico no qual ele foi produzido. Depois, os grupos socializavam as respostas com a turma sob a orientação do condutor da oficina e compartilhavam dificuldades e estratégias adotadas para cada 
gênero textual, como a observação da vestimenta da época no caso das fotografias ou a atenção à grafia quando o documento era textual. $\mathrm{Na}$ ausência desses elementos, até mesmo o tipo de grafia e o estado de conservação do papel eram recursos aos quais os alunos recorriam na tentativa de responder às questões norteadoras propostas.

Cabe frisar que a documentação utilizada era original, única e autêntica, sob a custódia da instituição de forma a proporcionar uma experiência diferenciada aos alunos que se deslocavam até a sede da instituição. ${ }^{10}$ Tal opção deve-se primeiro ao fato de que o acesso à documentação, desde que orientado no que diz respeito aos aspectos de sua preservação, deve ser amplo e irrestrito. Em segundo lugar, seria incoerente com o fato de no setor de Consulta o acesso ser livre a qualquer pessoa, desde que identificada ${ }^{11}$, o que geraria uma diferenciação entre 0 consulente "pesquisador" e o cidadão comum, separação que não se ampara em nenhuma evidência concreta quanto ao "perigo" ao qual estariam expostos os documentos. No que tange a esse assunto, a opção do NAE se alinha, ao menos em parte, ao proposto por Bellotto:

Na verdade, os arquivos estão premidos entre dois extremos: de um lado, a cultura para o usuário erudito e o cientista; de outro, a cultura para todos. E no bojo dessa diversificação vem também toda uma dicotomia na política de uso e liberalização de documentos. Será que, necessariamente, só àqueles dois primeiros públicos pode ser permitido o acesso aos documentos mais raros, aos de mais precário estado de conservação e aos de conteúdo mais complexo? É certo que esse usuário, o pesquisador, por definição pode prescindir da assistência que o cidadão comum requer. Mas, no que concerne à segurança e ao cuidado, a totalidade dos consulentes deve receber a mesma vigilância. Mesmo porque ao simples curioso não acudirá a tentação de apoderar-se de um documento do qual nem do valor real tem noção! (BELLOTTO, 2007, p. 241).

10 Entre os documentos utilizados sob a temática "Fontes Históricas" constavam, por exemplo, um título de eleitor datado de 1890, um decreto estadual de 1896, um mapa da província de São Paulo de 1886, produzido a mando da Sociedade Promotora de Imigração, e fotografias referentes ao Movimento Constitucionalista de 1932, entre outros documentos que procuravam demonstrar a diversidade do acervo da instituição.

${ }^{11}$ A exceção fica por conta do acervo DEOPS e outros que envolvem questões de honra e privacidade, nos termos do Decreto Estadual 58.052/2012, que regulamentou a Lei de Acesso à Informação no Poder Executivo do Estado de São Paulo (ARQUIVO PÚBLICO DO ESTADO, 2014b). 
Ao término do período em sala de aula, esperava-se que eles estivessem sensibilizados no que diz respeito aos aspectos importantes a serem observados na análise de documentos e, mais ainda, em relação à importância da sua preservação para a História e a garantia de seu acesso à população. Em seguida, era realizada uma breve pausa para a reorganização dos alunos e tinha início a segunda parte - visita mediada realizada por 2 a 4 integrantes do NAE com duração aproximada de 60 minutos.

Dividida em dois grupos de 15 a 20 alunos, a visita permitia que os alunos conhecessem os seguintes núcleos de trabalho da instituição: "Conservação", "Encadernação e Acondicionamento", "Textual Público", "Cartográfico" e "Atendimento ao Público". Essa "trilha ideal"12, foi pensada de forma que eles percorressem o "caminho do documento" de guarda permanente $^{13}$ ao ser recolhido à instituição: primeiro analisa-se as condições de conservação, depois se decide qual o acondicionamento ideal; em seguida, ele é direcionado à custódia de seu respectivo gênero documental ${ }^{14}$ para, depois do tratamento técnico ${ }^{15}$, ser disponibilizado seu acesso pelos consulentes.

12 Chamamos o percurso mencionado de trilha ideal porque às vezes, por questão de logística ou pelo número de alunos ser elevado (superior a 30 ) os alunos eram divididos em dois grupos, fazendo com que um deles fizesse o trajeto de forma invertida. A perda da trilha ideal era compensada com uma explicação inicial acerca do trajeto do documento e a menção ao fato de que eles fariam o percurso de forma não linear.

13 Os documentos de guarda permanente podem ser definidos como "aqueles cujas informações são consideradas imprescindíveis ao órgão produtor e para a comunidade. Esses documentos, além do valor administrativo, legal e fiscal, encerram também valor de prova e como fonte para a pesquisa e, portanto, devem ser definitivamente preservados." (BERNARDES; DELATORRE, 2008, p. 42).

${ }^{14} \mathrm{O}$ gênero documental é "a reunião de espécies documentais que se assemelham por seus caracteres essenciais, particularmente o suporte e o suporte formato, que exigem processamento técnico específico e, por vezes, mediação técnica para acesso" (ARQUIVO NACIONAL, 2005, p. 99). Os gêneros documentais mais comuns no Arquivo do Estado são os bibliográficos, cartográficos, filmográficos, iconográficos e textuais, além de uma ampla gama de títulos de periódicos, os quais costumam ser consultados para a produção de significativo número de teses e dissertações pelas universidades paulistas (SILVA; SILVA, 2016).

150 tratamento técnico refere-se às atividades de identificação, classificação, arranjo, descrição e conservação pelas quais o documento passa ao adentrar, de forma permanente, um arquivo. (ARQUIVO NACIONAL, 2005, p. 138). 
Finalizada a atividade como um todo (oficina + visita mediada), cuja duração, somada, tinha aproximadamente duas horas, esperava-se que os alunos: a) Fossem capazes de identificar as diferentes linguagens e gêneros textuais utilizadas como fontes históricas e suas funções básicas; b) conhecessem a rotina e do funcionamento do APESP; c) compreendessem a utilizar diferentes fontes de informação na aquisição e construção do conhecimento e; d) valorizassem o patrimônio arquivístico paulista sob a guarda da instituição.

No decorrer de três anos foram realizados 35 atendimentos, nos meses de março a junho, e de agosto a novembro, sendo 18 em 2013, 11 em 2014, e 6 em 2015, totalizando 1.079 alunos: 498, 378 e 203 alunos, respectivamente. O agendamento e participação ocorriam de forma gratuita tanto para escolas particulares como públicas. No período, 22 desses atendimentos foram realizados para escolas da rede pública de ensino (673 alunos no total) e 13 para a rede privada (406 alunos), a maioria na forma de livre demanda, isto é, com o agendamento ocorrendo de forma direta entre a escola e o Arquivo do Estado. A exceção fica por conta de 8 atendimentos ocorridos em 2014, fruto do convênio com a Fundação para o Desenvolvimento Educacional (FDE) ${ }^{16}$, celebrado a partir do diagnóstico obtido pelos atendimentos de 2013, no qual foi verificado que dos 13 atendimentos públicos, apenas 2 foram para escolas estaduais.

A razão para a pouca participação do público estadual, segundo os professores que entravam em contato com o APESP, era a dificuldade em se obter a verba necessária para o deslocamento dos alunos. No entanto, alguns atendimentos eram facilitados pela proximidade geográfica e outros pela verba cedida pela Secretaria Municipal às escolas, patrocínio que, na rede estadual, ocorria apenas para ações presentes no programa "Cultura é Currículo".

No que se refere ao perfil dos professores que optavam por trazer seus alunos ao Arquivo, em 30 ocasiões $(85,7 \%)$ havia ao menos um

\footnotetext{
16 O convênio foi oficializado em 22 de janeiro de 2014 e publicado na página 1 do Caderno Executivo I do Diário Oficial do Estado do Estado de São Paulo do dia $1^{\circ}$ de fevereiro de 2014. (SÃo PAULO, 2014).
} 
professor de História acompanhando a turma e nas poucas vezes em que isso não ocorreu, (3 delas) foi por motivo alheio à vontade do professor regente da turma ${ }^{17}$.

Ofertada para alunos do Ensino Fundamental ao Ensino Médio, a oficina teve forte apelo nos anos iniciais de cada segmento e teve mais da metade de seus atendimentos concentrada no $6^{\circ}$ ano e no $1^{\circ}$ ano do Ensino Médio, muito em razão de ser o ano escolar em que se trabalha, de forma mais ampla, os conceitos de fonte História e de memória. Em um recorte por segmento, $60 \%$ do público foi formado por alunos do Ensino Fundamental e $40 \%$ do Ensino Médio, como observamos no gráfico 1.

Gráfico 1 - Número de atendimentos por ano escolar: 2013-2015

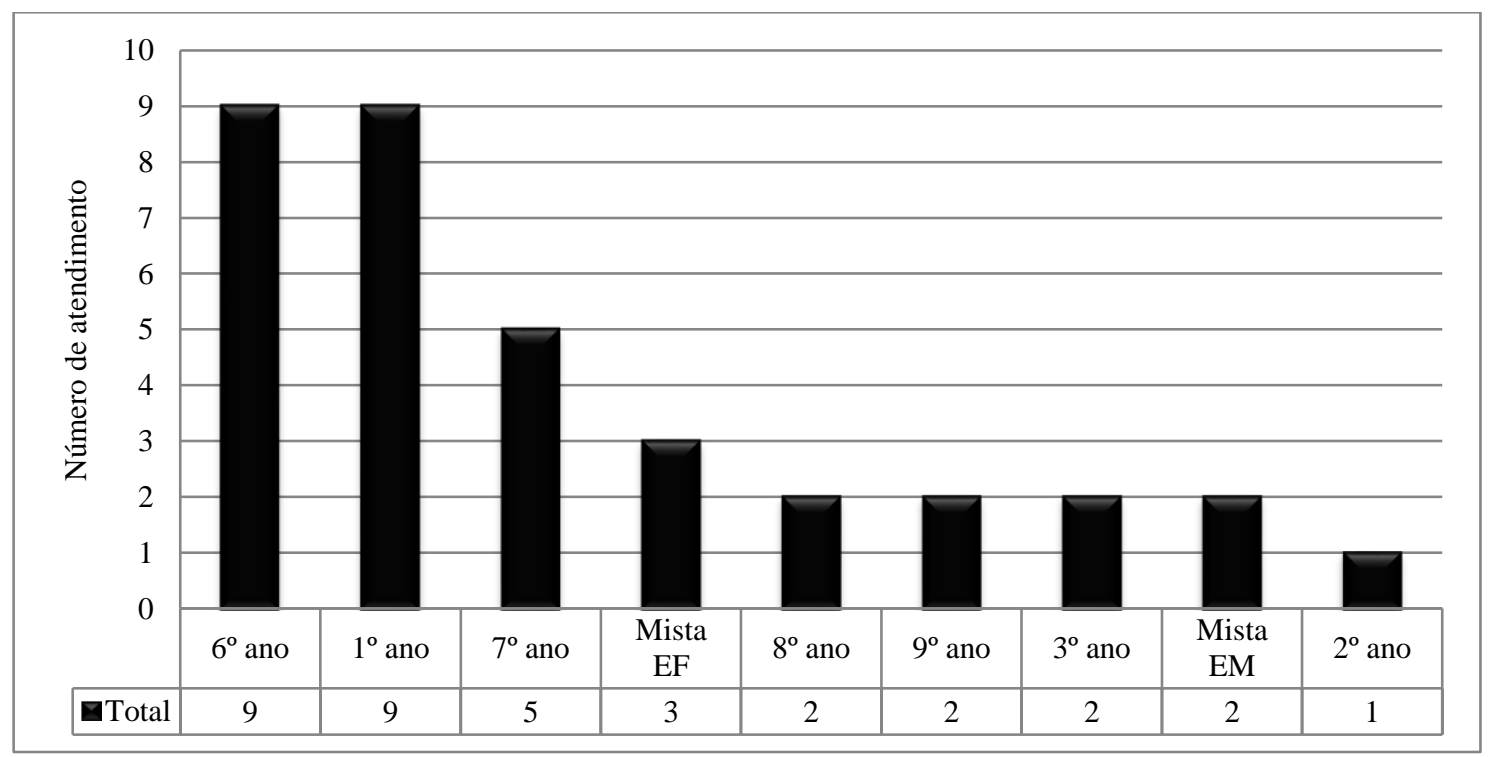

Fonte: Arquivo Público do Estado SP (2013, 2014a, 2015).

\footnotetext{
17 Em 2013 houve uma ocasião na qual o professor regente não acompanhou a turma devido à declaração de greve por parte do sindicato da categoria e, em 2014, em duas ocasiões, o dia da marcação, via FDE, não coincidiu com o dia no qual o professor lecionava na escola.
} 
Como já mencionamos, a proposta previa um tema generalista e outros específicos a serem abordados com os alunos, a critério do professor responsável. Entretanto, no universo dos temas oferecidos, situação de certa forma relacionada ao ano escolar das turmas atendidas, "Fontes Históricas" foi o mais solicitado e respondeu por 30 atendimentos, seguido pelas temáticas "Anistia e Redemocratização" (3), "Ferrovias Paulistas" (1) e "Movimento de 1932" (1). A primazia da temática "Fontes Históricas" $(85,7 \%)$ sobre as demais reside no fato de o tema, por ser mais abrangente e não ter uma ligação tão direta com conteúdos específicos da disciplina de História, permitir maior maleabilidade de adequação ao currículo e ao conteúdo trabalhado ao longo do ano escolar. Ter sido a única opção ofertada às escolas estaduais via FDE, também contribui para reforçar a tendência de concentração temática.

\section{Avaliação da atividade}

Ao final de cada atividade, era solicitado aos professores responsáveis pelas turmas o preenchimento de uma ficha-questionário. Verificando-as quanto aos aspectos operacionais, observamos, que no que se refere à divulgação, 24 a consideraram "excelente" e 11 "boa"; quanto ao agendamento, 30 o avaliaram como "excelente", e 5 o viram apenas como "bom". No que concerne à organização como um todo das fases da atividade, 33 analisaram-na como "excelente", ante 2 conceitos "bons". Por fim, no que diz respeito à localização da instituição, 34 julgaram-na "excelente" e apenas 1 a avaliou como "boa".

\section{Tabela 1 - Aspectos operacionais e pedagógicos do "A sala de aula no Arquivo".}

\begin{tabular}{|c|c|c|c|c|c|c|}
\hline \multirow[b]{2}{*}{ Avaliação } & \multicolumn{4}{|c|}{ Aspectos Operacionais } & \multicolumn{2}{|c|}{$\begin{array}{c}\text { Aspectos } \\
\text { Pedagógicos }\end{array}$} \\
\hline & Divulgação & Agendamento & Organização & Local & Condução & Visita \\
\hline Excelente & 24 & 30 & 33 & 34 & 34 & 34 \\
\hline Bom & 11 & 5 & 2 & 1 & 1 & 1 \\
\hline Regular & 0 & 0 & 0 & 0 & 0 & 0 \\
\hline
\end{tabular}




\begin{tabular}{lcccccc} 
Ruim & 0 & 0 & 0 & 0 & 0 & 0 \\
Total & 35 & 35 & 35 & 35 & 35 & 35 \\
\hline
\end{tabular}

Fonte: Arquivo Público do Estado SP (2013, 2014a, 2015).

Quando nos debruçamos sobre aspectos pedagógicos, isto é, o efetivo contato dos alunos com os membros do Núcleo de Ação Educativa $1^{\text {a }}$ etapa - e, depois, na visita às instalações, mediada pelo NAE e levada adiante com a colaboração dos técnicos dos setores ${ }^{18}$, o resultado é positivo, visto que apenas uma avaliação não identifica o trabalho pedagógico como "excelente", o que equivale a apenas 2,9\%.

Outro ponto que se destaca é que quanto mais a ação colocava o professor em contato direto com a instituição, a percepção no que diz respeito à instituição e seus servidores melhorou ${ }^{19}$, como podemos observar no gráfico 2, que mensura em termos percentuais os dados da tabela 1, a qual indica que $100 \%$ das visitas caracterizadas como "Excelente" ou "Bom".

\section{Gráfico 2 - Aspectos operacionais e pedagógicos do "A sala de aula no Arquivo": 2013-2015}

18 Os técnicos dos setores eram previamente avisados por meio de memorando. Desse modo, para a apresentação de seu local de trabalho, preparavam uma explicação sobre as atividades desenvolvidas e/ou realizavam apresentação da rotina no local.

19 Subdividindo os conceitos, observamos que à medida que o professor e a escola vivenciaram um contato mais próximo com o Arquivo (site/e-mail>telefone>participação na atividade) a avaliação positiva aumentou de $68,6 \%$ para $97,1 \%$. 


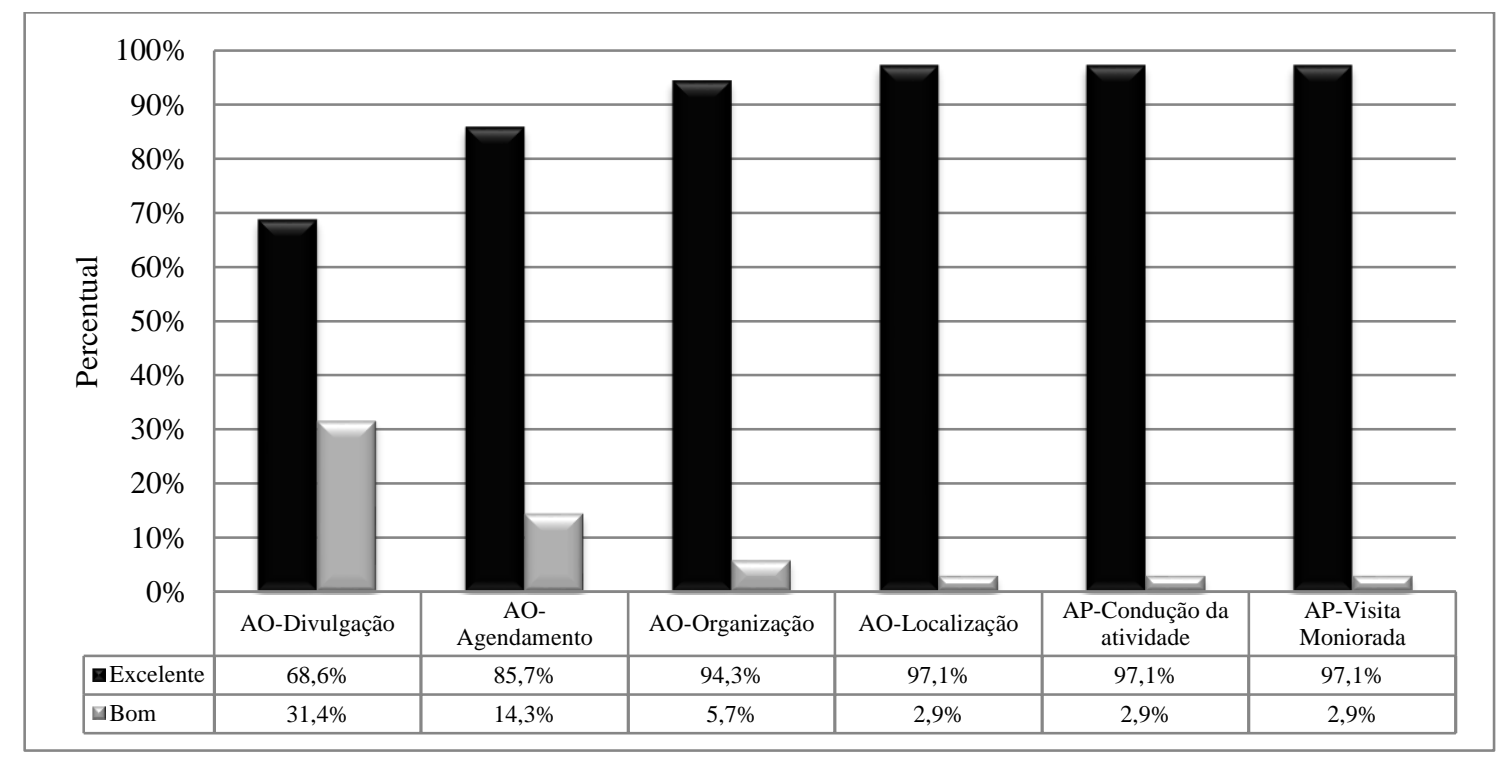

Fonte: Arquivo Público do Estado SP (2013, 2014a,2015).

Legenda: $A O=$ Aspectos Operacionais; $A P=$ Aspectos Pedagógicos

Uma preocupação da equipe no desenvolvimento da atividade era o quanto a vinda dos alunos ao APESP contribuiria em termos de conhecimento histórico, e em que medida ela se adequava às funções do NAE de difusão do acervo e sensibilização para a preservação do patrimônio histórico-documental. Nesse sentido, era solicitado ao professor, também, que avaliasse a atividade assinalando quais contribuições a experiência teria trazido aos alunos.

Tabela 2 - Contribuições para o aprendizado dos alunos: 2013-2015

\begin{tabular}{lll}
\hline Item & Sim & Não \\
\hline Passar a conhecer as atribuições do Arquivo Público do Estado & 33 & 2 \\
& & \\
\hline
\end{tabular}


Ter contato direto com fontes primárias

Obter informações de documentos textuais, iconográficos e

cartográficos

Conhecer, por meio dos documentos, eventos históricos de São

Paulo

Reconhecer a importância da preservação do patrimônio histórico-documental

Fonte: Arquivo Público do Estado SP (2013, 2014a, 2015).

Com base na tabela 2, podemos afirmar que a atividade dialogava fortemente com as funções do Núcleo de Ação Educativa, visto que "passar a conhecer as atribuições do Arquivo Público do Estado" foi o elemento mais assinalado, demonstrando que a visita aos setores do APESP cumpriu um papel pedagógico importante para eles. Em seguida, as opções referentes ao contato com a documentação original do arquivo, "fontes primárias"20, à importância da preservação do patrimônio histórico-documental e a obter informações de gêneros textuais variados também foram assinaladas pela maioria. Fator que é representativo também, tanto em relação à visita quanto ao trabalho desenvolvido na oficina em sala de aula, por meio da mediação pedagógica realizada.

A opção menos assinalada foi a referente ao conhecimento de eventos históricos por meio dos documentos. Embora pudesse ser até uma intenção legítima por parte dos professores, era um aspecto secundário no momento de criação da atividade. No entender da equipe, o fundamental era os alunos compreenderem a potencialidade e a importância do patrimônio histórico-documental para a cultura, a pesquisa de caráter histórico, e o papel do Arquivo Público do Estado na consecução desse fim.

Do mesmo modo, esperava-se que os professores enxergassem na instituição um parceiro em potencial para o desenvolvimento da criticidade em relação ao trabalho com documentos para além do livro didático e do cotidiano em sala de aula. Em termos percentuais, o diagnóstico

\footnotetext{
20 No momento de elaboração da ficha de avaliação, optou-se pela expressão "fontes primárias" por ser de uso corrente pelos historiadores e professores o que facilitaria, assim, a compreensão por parte do respondente. Sobre a problemática referente à utilização do termo e a categorização da "informação historiográfica", ver Aróstegui (2006), especialmente o capítulo "O processo metodológico e a documentação histórica".
} 
retrospectivo é favorável aos objetivos propostos, visto que entre cinco itens possíveis, quatro foram assinalados por mais de $80 \%$ dos professores participantes.

Gráfico 3 - Contribuições do "A sala de aula no Arquivo" para o aprendizado dos alunos: 2013-2015 (\%)

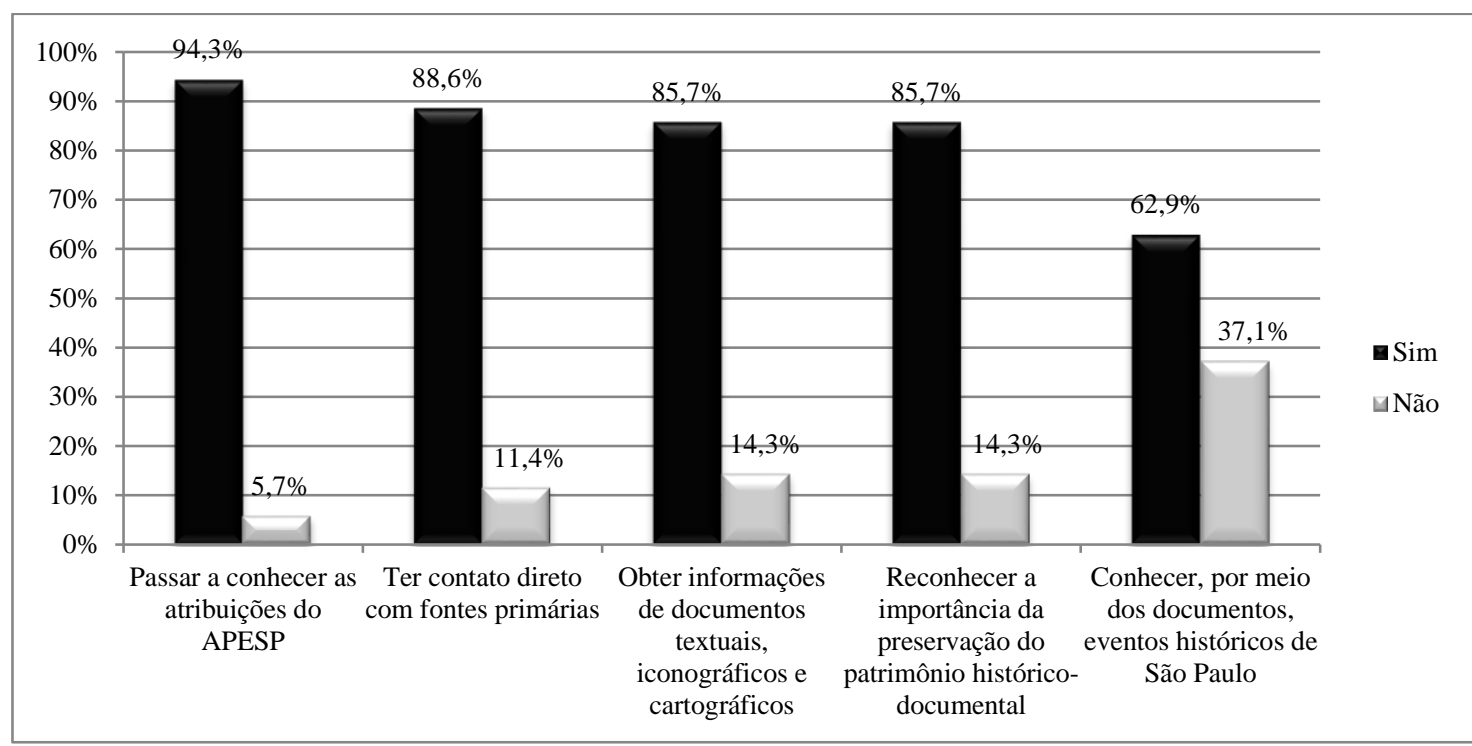

Fonte: Arquivo Público do Estado SP (2013, 2015).

A experiência, obviamente, apesar de bem avaliada, tinha suas limitações: um ponto observado que influenciava o resultado da atividade, por exemplo, era o professor ter ou não desenvolvido previamente algum trabalho correlato com os alunos; ou ela estar inserida em algum projeto ou algo parecido. No diálogo, tal questão era sondada informalmente, e o aproveitamento quando a resposta era positiva, tendia a ser melhor nessas ocasiões.

Destacamos, positivamente, o impacto da visita às instalações e da compreensão do quão complexo é o trabalho de recolhimento, preservação e garantia do acesso à documentação que subsidia a produção do conhecimento histórico - acadêmico e escolar - e que, a partir de então, passaram a conhecer. A professora responsável pela turma de 17 de abril de 2013, assim comentou a experiência em avaliação: 
Os alunos voltaram muito empolgados e mesmo aqueles que poucas coisas motivam, voltaram encantados. Nas aulas que se seguiram à atividade no arquivo fizemos uma discussão muito legal sobre a importância da preservação dos documentos e sobre o trabalho do historiador. Eles adoraram "tocar" nos documentos históricos e colocar máscara e luva, assim como ficaram fascinados ao conhecer todo o processo de preservação do documento e em entrar e ver os $12 \mathrm{~km}$ de documentação! Relataram isso empolgadíssimos! A atividade cumpriu seu objetivo e concluiu um trabalho de um bimestre onde discuti com eles o processo de escrita da história e seus desdobramentos. ${ }^{21}$

Interessante ressaltar a menção da professora ao fascínio despertado nos alunos quando entraram em contato com os documentos e, igualmente, precisaram usar máscara e luva. Essa observação revela o acerto na decisão de colocá-los em contato direto com o acervo original, visto que, em última instância, a ação cumpre um papel lúdico e de aguçamento dos sentidos, da mesma maneira que o percurso pelas instalações, o qual proporciona uma experiência ímpar ao permitir-lhes conhecer por dentro um edifício especialmente projetado para ser um arquivo.

Comentário parecido, dessa vez de outra professora referente à turma do dia 10 de abril de 2015, vai ao encontro da citação acima ao registrar o seguinte texto: "Parabéns ao Núcleo de Ação Educativa pela contribuição ao trabalho do professor. Meus alunos ficaram encantados". O fato de os alunos expressarem o "encantamento" nos dois relatos, de forma alguma, em nossa compreensão, significa uma banalização das atividades. Ocorre, na verdade, justamente o contrário, ou seja, quanto mais "encantados" eles ficam, melhor a experiência pedagógica, como bem observa o PCN de História:

Além de gratificante, é altamente instrutivo para professor e alunos o trabalho que envolva saídas da sala de aula ou mesmo da escola para visitar um museu, ir a uma exposição de fotografias ou de obras de arte, conhecer um sítio arqueológico etc. Estes momentos são geralmente lúdicos e representam oportunidades especiais para que todos se

${ }^{21}$ Essa avaliação foi encaminhada por e-mail e não realizada logo ao término da visita por conta da impossibilidade, no próprio dia, de ela receber a ficha e preenchê-la no local. 
coloquem diante de situações diferentes, em atividades especiais de acesso a outros tipos de informação e de envolvimento com as vivências sociais mais amplas da sociedade e do conhecimento humano. As visitas aos locais são recursos didáticos favoráveis ao envolvimento dos alunos em situações de estudo, estimulando interesse e participação. Propiciam contatos diretos com documentos históricos, incentivando os estudantes a construírem suas próprias observações, interrogações, especulações, indagações, explicações e sínteses para questões históricas. Nessas visitas, deve-se destacar para os alunos o fato de que irão conhecer espaços especiais de preservação e de divulgação de patrimônios históricos e culturais. (BRASIL, 1998, p. 89-90).

O preparo dos servidores no relacionamento com a escola, tanto operacional como pedagogicamente, se mostrou um elemento diferencial no momento a avaliação realizada pelos profissionais responsáveis pelas turmas. "A sala de aula no Arquivo" demonstrou ser um canal frutífero de difusão do Acervo do APESP, permitindo à instituição cumprir com uma de suas atribuições constante no decreto no 54.276, que diz ser função do Departamento de Preservação e Difusão do Acervo "propor e coordenar programas de ação educativa, social e editorial com a finalidade de aproximar o Arquivo Público do Estado de instituições educacionais e da sociedade" (SÃO PAULO, 2009).

\section{Considerações Finais}

A análise da trajetória do ensino de História no país nos permite compreendê-la como objeto de ação social, como bem exemplifica a Lei de Diretrizes e Bases da Educação Brasileira - LDB, no referente ao que deve ser ensinado. Isso significa, em última instância, a continuidade da tendência histórica de considerar o Ensino de História uma questão de Estado, isto é, tendo papel chave na formação da consciência nacional ancorada, todavia, no desenvolvimento concomitante de competências que permitam aos alunos intervirem de forma ativa no meio social no qual estão inseridos. 
As políticas educacionais estaduais para o Ensino de História colocaram em evidência a potencialidade dos Arquivos na proposição de atividades direcionadas ao público escolar, ou mesmo reconheceram-no como ferramenta importante para a escola, em razão de seu caráter histórico e patrimonial. Nesse contexto, por serem guardiões da documentação produzida pelo Estado e circunstancialmente tendo, sob sua custódia, documentos para além da administração pública, os Arquivos têm a potencialidade e as condições de serem interlocutores das instituições de ensino na produção do conhecimento, não só o acadêmico, mas igualmente o desenvolvido em sala de aula, o qual, ainda que diferente, não é menos importante.

"A Sala de aula no Arquivo" atendeu às expectativas dos professores que, ao retirá-los do cotidiano da sala de aula para conhecer o Arquivo, conseguiu que estes reconhecessem a importância da preservação do patrimônio histórico-documental, experimentassem de forma direta o contato com fontes históricas, no caso a documentação de guarda permanente, e realizassem uma atividade de análise e obtenção de informação através do contato com gêneros documentais variados.

Por outro lado, o Arquivo do Estado obteve êxito em abrir suas instalações, por meio de uma atividade pedagogicamente elaborada a um público não tão rotineiro e usuário de seus serviços, e se pôs em contato com um setor importante da sociedade que, de outra forma, não teria uma experiência tão positiva em uma instituição cuja existência serve, na visão de alguns, apenas à administração.

Os Arquivos públicos, e o Arquivo do Estado em especial, não podem e não devem abrir mão dessa relação, sob o risco de descolarem-se cada vez mais da sociedade na qual estão inseridos. É abrindo suas portas a um público cada vez mais amplo e diverso em termos de escolarização e de faixa etária que ele manterá seu papel de aparelho cultural relevante, o que não significa, de forma alguma, abrir mão das outras funções que desempenha em termos de disseminador de normas e procedimentos 
arquivísticos para as respectivas administrações às quais estejam vinculados.

Marc Bloch (2001) escreveu uma frase memorável dentre outras, presentes em seu pequeno e fundamental livro póstumo Apologia da história, ou o ofício do historiador: "Pois não imagino, para um escritor, elogio mais belo do que saber falar, no mesmo tom, aos doutos e aos escolares". Refletindo sobre a experiência do Arquivo Público do Estado de São Paulo e o panorama atual das ações de difusão cultural e ação educativa nas instituições congêneres do país, acreditamos que talvez seja esse, também, o desafio a ser encampado pelos Arquivos no que se refere à difusão de seus acervos: falar aos doutos e aos escolares.

\section{Bibliografia}

ABUD, Kátia Maria. História e o ensino temático. In: BLAJ, I.; MONTEIRO, J. (org.). História e utopia. São Paulo: ANPUH, 1996. p. 492-501.

ABUD, Kátia Maria. Currículos de história e políticas públicas: os programas de História do Brasil na escola secundária. In: BITTENCOURT, C. (org.). $O$ saber histórico na sala de aula. 10 ed. São Paulo: Contexto, 2005. (Coleção Repensando o Ensino). p.12-28

ALVES, Clarisse; BRANDO, Nôva; MENEZES, Vanessa. Ação educativa e educação patrimonial em arquivos: a oficina "resistência em arquivo: patrimônio, ditadura e direitos humanos" no APERS. OPSIS, Catalão, v.15, n. 1, p. 9-27, 2015.

ARÓSTEGUI, Julio. A pesquisa histórica: teoria e método. Bauru, SP: Edusc, 2006.

ARQUIVO NACIONAL. Dicionário brasileiro de terminologia arquivística. Rio de Janeiro: Arquivo Nacional, 2005. (Publicações Técnicas, n. 51).

ARQUIVO PÚBLICO DO ESTADO (São Paulo). Avaliação da atividade "A sala de aula no Arquivo". 2013. [18 avaliações preenchidas pelos professores].

ARQUIVO PÚBLICO DO ESTADO (São Paulo). Avaliação da atividade "A sala de aula no Arquivo". 2014a [11 avaliações preenchidas pelos professores].

ARQUIVO PÚBLICO DO ESTADO (São Paulo). Política pública de arquivos e gestão documental do Estado de São Paulo. 2. ed. rev. e ampl. São Paulo: Arquivo Público do Estado, 2014b. 
ARQUIVO PÚBLICO DO ESTADO (São Paulo). Avaliação da atividade "A sala de aula no Arquivo". 2015. [6 avaliações preenchidas pelos professores].

BACELLAR, Carlos de Almeida Prado. Acesso à informação, direito à memória: os arquivos públicos em questão. Cad. Pesq. Cdhis, Uberlândia, v. 25, n. 2, p. 265-276, jul./dez. 2012.

BARBOSA, Andresa Cristina Oliver; PEREIRA, Carla Janaína de Freitas; MENEZES, Caroline Grassi Franco de. Conociendo el Deops/SP: historia y memoria. In: CONGRESSO DE EDUCACIÓN, MUSEOS Y PATRIMONIO. MEMORIAS DE HOY, APRENDIZAJES DEL FUTURO, 4., 2011, Chile. Anais [...]. Chile: DIBAM, 2011.

BARBOSA, Andresa Cristina Oliver; SILVA, Haike Roselane Kleber. Difusão em arquivos: definição, políticas e implementação de projetos no Arquivo Público do Estado de São Paulo. Acervo: Revista do Arquivo Público Nacional, Rio de Janeiro, v.25, n.1, p.45-66, jan./jun. 2012.

BARBOSA, Andresa Cristina Oliver; PEREIRA, Carla Janaína de Freitas; SILVA, Stanley Plácido da Rosa. Ação educativa a distância: relato de uma prática com professores no Arquivo Público do Estado de São Paulo. Revista História Hoje, São Paulo, v. 3, n. 5, p. 125-146, 2014.

BELLOTTO, Heloisa Liberalli. Arquivos permanentes: tratamento documental. 4 ed. Rio de Janeiro: FGV, 2007.

BENEVIDES, Maria Victoria de Mesquita. Educação para a democracia. Lua Nova: Cultura e Política, São Paulo, n. 38, p. 223-237, dez. 1996.

BERNARDES, Ieda Pimenta; DELATORRE, Hilda. Gestão documental aplicada. São Paulo: Arquivo Público do Estado, 2008.

BEZERRA, Holiem Gonçalves. Ciências humanas e suas tecnologias história. Brasília, [2004]. Disponível em:

http://portal.mec.gov.br/seb/arquivos/pdf/11Historia.pdf. Acesso em: 20 mar. 2018.

BLOCH, Marc. Apologia da história, ou o ofício do historiador. Rio de Janeiro: Jorge Zahar, 2001.

BRASIL. Parâmetros Curriculares Nacionais: História. Brasília: MEC/SEF, 1998.

CONSELHO INTERNACIONAL DE ARQUIVOS. Declaração Universal sobre Arquivos. 2010. Disponível em:

http://www2.iict.pt/archive/doc/ICA_2010_Universal-Declaration-onArchives_PT_1_.pdf. Acesso em: 26 mar. 2018. 
DURAN, Marília Claret Geraes; ALVES, Maria Leila; PALMA FILHO, João Cardoso. Vinte anos da política do ciclo básico na rede estadual paulista. Cadernos de Pesquisa, São Paulo, v. 35, n. 124, p. 83-112, jan./abr. 2005.

FONSECA, Thais Nivia de Lima e. História \& ensino de história. 2 ed. Belo Horizonte: Autêntica, 2004.

GIGANTE, Moacir. Reformas curriculares do ensino de história no Estado de São Paulo: da resistência à ditadura militar ao refluxo conservador. Educação: Teoria e Prática, Rio Claro, v. 5, n. 8, jan./jun. 1997.

GOHN, Maria da Glória. Movimentos sociais na contemporaneidade. Revista Brasileira de Educação, Rio de Janeiro, v. 16, n. 47, maio/ago. 2011.

LE GOFF, Jacques. História e memória. 5. ed. Campinas, SP: Unicamp, 2003.

MARTINS, Maria do Carmo. A CENP e a criação do currículo de história: a descontinuidade de um projeto educacional. Revista Brasileira de Educação, Rio de Janeiro, v. 18, n. 36, p. 39-60, 1998.

PALMA FILHO, João Cardoso. A reforma curricular da Secretaria de Educação do Estado de São Paulo para o ensino de 10 grau (1983-1987): uma avaliação crítica. 1989. Dissertação (Mestrado em Educação) Pontifícia Universidade Católica de São Paulo, São Paulo, 1989.

RIBEIRO, Renilson Rosa. O saber (histórico) em parâmetros: o ensino da história e as reformas curriculares das últimas décadas do século XX. Mneme: Revista de Humanidades, Caicó, v. 5, n. 10, abr./jun. 2004.

SÃO PAULO (Estado). Coordenadoria de Estudos e Normas Pedagógicas. Proposta curricular para o ensino de história - $1^{\circ}$ grau. São Paulo: SEE/CENP, 1989.

SÃO PAULO (Estado). Decreto no 54.276 de 27 de abril de 2009. Reorganiza a Unidade do Arquivo Público do Estado, da Casa Civil, e dá providências correlatas. São Paulo: Assembleia Legislativa, 2009. Disponível em: http://www.arquivoestado.sp.gov.br/pdfs/Decreto\%20n.55.276.pdf. Acesso em: 8 mar. 2018.

SÃO PAULO (Estado). Casa Civil. Processo CC 145274/2012. Convênio de conjugação de esforços para alunos da Rede Estadual de Ensino realizar visitas orientadas ao Arquivo Público, no âmbito do projeto "Lugares de Aprender: A Escola Sai da Escola". Diário Oficial do Estado de São Paulo: Poder Executivo, Seção I, São Paulo, SP: Imprensa Oficial, v. 124, n. 22, p. 1, 1 fev. 2014. Disponível em: www.imprensaoficial.com.br. Acesso em: 8 mar. 2018. 
SILVA, Haike Roselane Kleber da; SILVA, Stanley Plácido da Rosa. O Arquivo Público do Estado de São Paulo e a historiografia da pós-graduação paulista. ÁGORA: Arquivologia em debate, Florianópolis, v. 26, n. 53, p. 141-170, dez. 2016.

SOUZA, Rosa Fátima de. Política curricular no Estado de São Paulo nos anos 1980 e 1990. Cadernos de Pesquisa, São Paulo, v. 36, n.127, abr. 2006.

Recebido em 26 de junho de 2018 Aceito em 07 de outubro de 2019 